\title{
UNA CURIOSA INSCRIPCIÓN HEBREA DEL SIGLO XIX EN EL CASTILLO DE GUADAMUR (TOLEDO)
}

\author{
ANA MARÍA LÓPEZ ÁLVAREZ \\ SANTIAGO PALOMERO PLAZA \\ Museo Sefardi. Toledo
}

La inscripción que vamos a estudiar se encuentra en la villa de Guadamur, situada a $14 \mathrm{~km}$. al SW. de Toledo entre la comarca de la Sisla y los montes Sisla de Noez. Como su nombre indica es de origen árabe y su traducción más común es la de "río de paso» '.

Esta villa es conocida especialmente porque en su cercanía se encontró el tesoro visigodo más importante de los conocidos hasta hoy: el de Guarrazar. Sin embargo, es notable también por su castillo, uno de los que se encuentra en mejor estado de conservación en la provincia de Toledo, después de la restauración a que fue sometido en el siglo XIX.

Se levanta sobre una colina denominada Cerro de la Natividad o del Castillo ${ }^{2}$, denominado también Cerro de la Ermita ${ }^{3}$. El permiso de construcción fue concedido en 1468, según documento otorgado por el rey Enrique IV, a don Pedro López de Ayala «el mozo» ${ }^{4}$,

' L. Moreno Nieto, Diccionario enciclopédico de Toledo y su provincia. Toledo, 1974. En la página 181. "La villa de Guadamur, como su nombre lo indica, es de origen árabe, según el académico Fernández y González, significa "río de paso"”.

${ }^{2}$ L. MORENo Nieto, op. cit., pág. 181.

3 J. M. Ruiz Alonso, Guadamur, historia del castillo y de sus gentes. Toledo, 1984. "Situado al E. de la villa, en el cerro llamado de la ermita, promontorio de escaso relieve...".

${ }^{4}$ Ibid., pág. 58: «Don Enrique por la gracia de Dios rrey de Castilla ... por quanto vos Pero Lopes de Ayala my alcalde mayor de la muy noble cibdad de Toledo e del mi consejo me fesysteis rrelacion que seyendo como soys señor de la villa de Guadamur donde thenedes juridicion cevyl e criminal mero mysto ynperio, dis que para guarda de vuestra persona como para conformacion de vuestro estado e de aquellos que de vos decendieren aveys principiado faser e hedificar en la dicha villa un castillo e casa fuerte lo qual como quier que desydes que de justicia e derecho lo podistes faser e acabar el dicho castillo e casa ... pidiendome eso mismo por merced diese licencia e facultad ... yo considerando las causas susodichas e acatando los muchos e buenos e leales servicios que vos el dicho Pero Lopes de Ayala me avedes 
quien, como su padre, ocupó los puestos de alcalde mayor de Toledo y aposentador real. En el año 1470 recibió el título de conde de Fuensalida. Ya en el año de 1555 era Guadamur un lugar con población estable porque en esta fecha «... el tercer conde de Fuensalida y señor del castillo y de la villa, otorgó testamento, cuya copia se conserva en el archivo del Ayuntamiento, en virtud del cual dejaba a sus vasallos de Guadamur las tierras que venían cultivando, con la condición de pagarle un pequeño censo" ".

Fue Guadamur villa de señorío nobiliario desde 1446 hasta 1843, estando vinculado el castillo hasta esa fecha a los condes de Fuensalida y Frías. Don Bernardino Fernández de Velasco, XV duque de Frías y presidente algún tiempo en 1838 del gobierno de María Cristina, firmó en 1843 «un contrato de cesión de sus propiedades señoriales en Guadamur a los vecinos de dicha villa» ${ }^{\text {. }}$

Mucho sufrió el castillo a partir de este momento hasta que en 1897 fue adquirido por don Carlos Morenés y Tord, Barón de las cuatro Torres, conde del Asalto, pariente lejano de los Ayala a quien debemos su reconstrucción. Para ello se rodeó de un equipo de eruditos y conocedores del arte y de la historia, que fueron los artífices del armonioso conjunto que hoy contemplamos. Entre ellos debemos mencionar la colaboración del conde de Cedillo ${ }^{7}$ con quien recorrió distintos lugares de España para adquirir objetos e inspirarse en los estilos que son manifiestos en el castillo, cuando no era factible adquirir originales. A cargo de éste "corrieron las inscripciones góticas de los frisos y escocias. Para alguna de ellas se basó en los restos encontrados" " ${ }^{8}$. Asimismo se trajeron expertos en

fecho e fasedes de cada día ... vos apruevo e confirmo el dicho castillo e casa fuerte que asy avedes fecho e hedificado en la dicha vuestra villa de Guadamur e vos do e otorgo licencia poder e facultar por la acabar e fenescere para que podades faser e hedificar e acabar... (Madrid, 24 de julio de 1468)".

5 Ibid., pág. 65: “Iten mando que la dehesa nueva de Guadamur que el conde mi tío aparto del dicho termino para hacer dehesa que por quanto es valdio y termino comun del dicho lugar que le sea restituido al dicho concejo...».

${ }^{6}$ Ibid., pág. 68

7 Personaje de una gran cultura humanística. Doctor en Filosofia y Letras. Miembro de la Academia de la Historia. Autor del Catálogo Artístico Monumental de Toledo y su Provincia, obra que le encargó el general Primo de Rivera. Su realización le ocupó varios años y es una obra a la que hoy todavía se hace referencia. Este trabajo le permitió conocer en profundidad la historia y la cultura de la ciudad y de su provincia.

8 J. M. Ruiz Alonso, op. cit., pág. 136. 
todas las artes, «el pueblo asistió a unos años de actividad febril con el trasiego incesante de peones y de alarifes, el acarreo de materiales, las correrías de anticuarios, las visitas de ilustres amigos y el ir y venir de carretas cargadas de mobiliario y de utillaje. Pero también el conde del Asalto propuso que estos expertos hiciesen escuela y que los habitantes del pueblo que estuviesen interesados pudieran aprender las más antiguas técnicas de artesanía para que éstas no se perdieran (armaduras, cuero, yeserías, etc.). Tenemos noticia que el artesano toledano Higinio Lorente que realizó las armaduras que adornan el castillo formó parte de estos artesanos. Hoy su hijo es quien sigue la tradición de su padre" ?.

Se propusieron, tanto el conde de Asalto como el de Cedillo, devolver al castillo su pasado esplendor; suponemos que notablemente influidos por el romanticismo decadente y por el gusto por lo medieval predominante en el siglo XIX. Todos los estilos tardomedievales y el primer Renacimiento se vieron hermanados ${ }^{10}$.

El castillo, tal y como lo contemplamos hoy, presenta una planta cuadrada, en medio de la cual se abre un hermoso patio al que dan las habitaciones. En los ángulos, torres circulares con saeteras al interior y troneras en el exterior; con foso entre la muralla y la fortaleza, y puente levadizo bien conservado ". En el ángulo de poniente se levanta majestuosa la torre del homenaje. La descripción más atinada nos la proporciona el vizconde de Palazuelos 12: «Embebidos en los muros nótanse repetidamente no pocos escudos con el blasón de Ayala, reducido a dos lobos pasantes y en derredor, a guisa de orla, ocho aspas o cruces de San Andrés. La portada, aunque sencilla, es linda y de marcado sabor de época. Redúcese a un arco

\footnotetext{
${ }^{9}$ Certamen nacional de fotografla sobre artes y tradiciones populares. Ministerio de Cultura, Madrid 1985, págs. 124-125.

10 J. M. Ruiz Alonso, op. cit., pág. 13: "Gótico tardío, Isabel, Mudéjar, algo del Quattrocento, se dan cita en sus estancias y nos acercan a comprender la visión romántica que sus restauradores - Intelectuales del siglo XIX - tenían sobre el mundo tardo medieval".

"Vizconde de Palazuelos, "El castillo de Guadamur», Toledo, publicación quincenal ilustrada, miércoles 1 de mayo de 1989, pág. 2: “Vese compuesto el castillo de dos recintos amurallados y paralelos entre sí, circuidos por el ancho foso cuya escarpa y contra-escarpa acusan en sus sinuosas líneas la disposición interior de los recintos. Los baluartes de los ángulos, en uno y otro de éstos, afectan la figura de torres circulares, y los que avanzan en la parte céntrica de las cortinas, la de los redientes, o torres tajamadas, así dichas por su semejanza con los tajamares de los puentes".

12 Ibid., pág. 3.
} 
de medio punto, formado por grandes dovelas e inscrito en un recuadro entre cuya parte superior y el arco campean tres graciosos escudos colocados en un mismo plano y en forma de losange; en el central se repiten las armas de los Ayalas y en los laterales izquierdo y derecho se destacan las de Castañeda y Silva, consistentes estas últimas en un león rampante vuelto hacia la izquierda, y en cuatro bandas con colillas de armiños, las de Castañeda».

En una visita al castillo descubrimos, en la habitación conocida como "habitación árabe", por los motivos que alberga muy del gusto de la época, bajo el artesonado, un friso dorado sobre el que está trazada una inscripción hebrea en letras de color azul añil, que recorre los cuatro muros de la misma. Se encuentra en perfecto estado de conservación, salvo en una parte del muro Este, donde una gotera la ha dañado gravemente. La citada inscripción se inicia en este mismo muro, sólo que al lado opuesto, y en ella leemos:

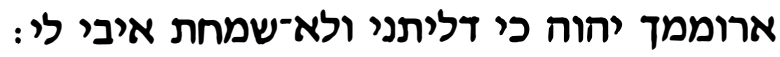

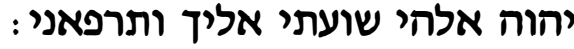

$$
\begin{aligned}
& \text { יהוה העלית מן־שאול נפשי חייתני מיורדי־בור: }
\end{aligned}
$$$$
\text { זמרו ו... }
$$

Se trata de los versículos 2-4 y la primera palabra del 5 del Salmo número 30:

"Te ensalzaré Yahvé porque me has liberado y no has regocijado a mis rivales a mi costa / Yahvé mi Dios, clamé a Ti y me has sanado. ¡Oh Yahvé, del abismo has sacado mi alma, me has hecho revivir de entre quienes bajan a la fosa!/ Cantad a...”

aquí finaliza la inscripción evidentemente por falta de espacio.

No deja de sorprendernos la existencia de esta inscripción en una estancia donde evidentemente los motivos decorativos son inequívocamente de gusto árabe. Al tratar de los cubillos y dormitorios del palacio que fueron decorados en estilos distintos, Ruiz Alonso ${ }^{13}$ nos habla de los gustos de sus restauradores. No podemos asegurar que el conde de Cedillo se inspirase en las inscripciones de una

13 J. M. Ruiz Alonso, op. cit., pág. 143: «... a veces predominaba lo renacentista, como los frescos a imitación de Fra Angelico de uno de los cubillos; a veces lo mudejar con estucos bellamente trabajados donde sin embargo se han sustituido las inscripciones cúficas por las hebraicas (tal vez reminiscencias de las sinagogas toledanas)". 
sinagoga toledana, que evidentemente tenía que ser la del Tránsito, que es la única que las posee. De lo que sí estamos seguros es de que entre las inscripciones que adornan la galería de mujeres de la sinagoga del Tránsito se encuentra el citado Salmo, aunque del mismo sólo se conserva el versículo primero, ya que el resto formaba parte del conjunto de yeserías destruido ${ }^{14}$. Si la hipótesis apuntada por José María Ruiz Alonso es cierta, hemos de suponer que es el momento en que el conde de Cedillo toma nota de esta inscripción de los muros de la galería de mujeres de la sinagoga del Tránsito, ésta se hallaba menos deteriorada que en el día de hoy, teniendo en cuenta que en 1877 se declaró a la sinagoga Monumento Nacional y que partir de 1880 la Comisión de Monumentos aceptaba la propuesta de Francisco Isidori y Ronda para su restauración, colocándose en el interior del edificio un andamio que, a pesar de haber sido terminados los trabajos en 1883, seguía montado en 1890 cuando la estudia el Vizconde de Palazuelos y en 1905 cuando lo hizo Rodrigo Amador de los Ríos. No puede, pues, extrañarnos el deterioro causado por esta situación. Nosotros mismos hemos recogido fragmentos perdidos de estas inscripciones, procedentes de la galería de mujeres, en los sótanos de la Casa Museo del Greco ${ }^{13}$.

\footnotetext{
14 F. Cantera Burgos, Sinagogas espatiolas, con especial estudio de la de Córdoba y la toledana de El Tránsito, reimpresión, Madrid 1984, págs. 141-142: “... se continúa con el salmo 30, v. 1, que se interrumpe pronto por haber desaparecido la ornamentación de las paredes en el lamentable abandono en que se ha tenido (jy ojalá no se tuviera aún!)».

15 A. M." López Álvarez, y Y. Álvarez Delgado, "La galería de mujeres de la Sinagoga de El Tránsito. Nuevos hallazgos", Sefarad, XLVII (1987) 301-314 + una lám.
} 


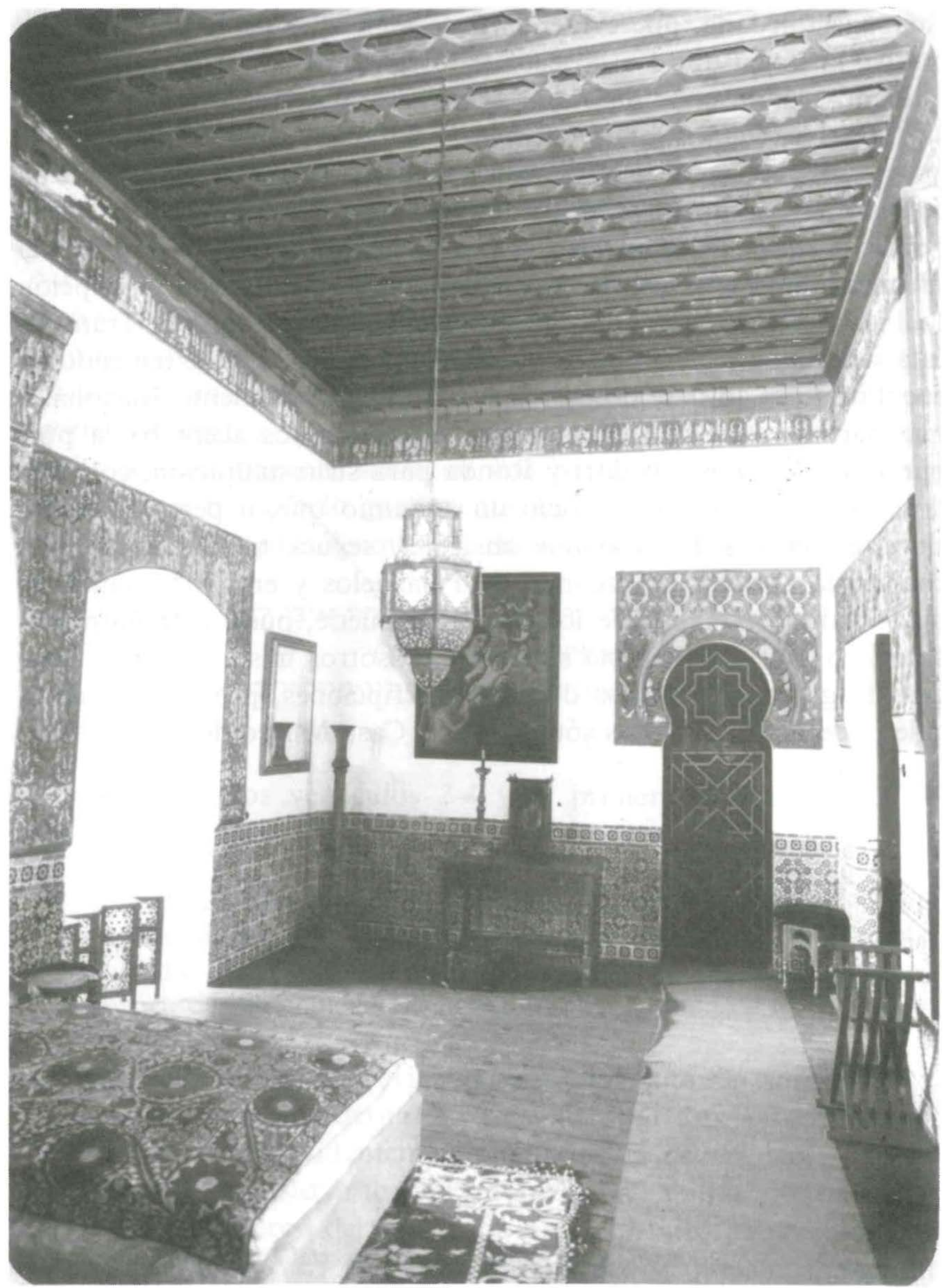

Habitación árabe

(c) Consejo Superior de Investigaciones Científicas 


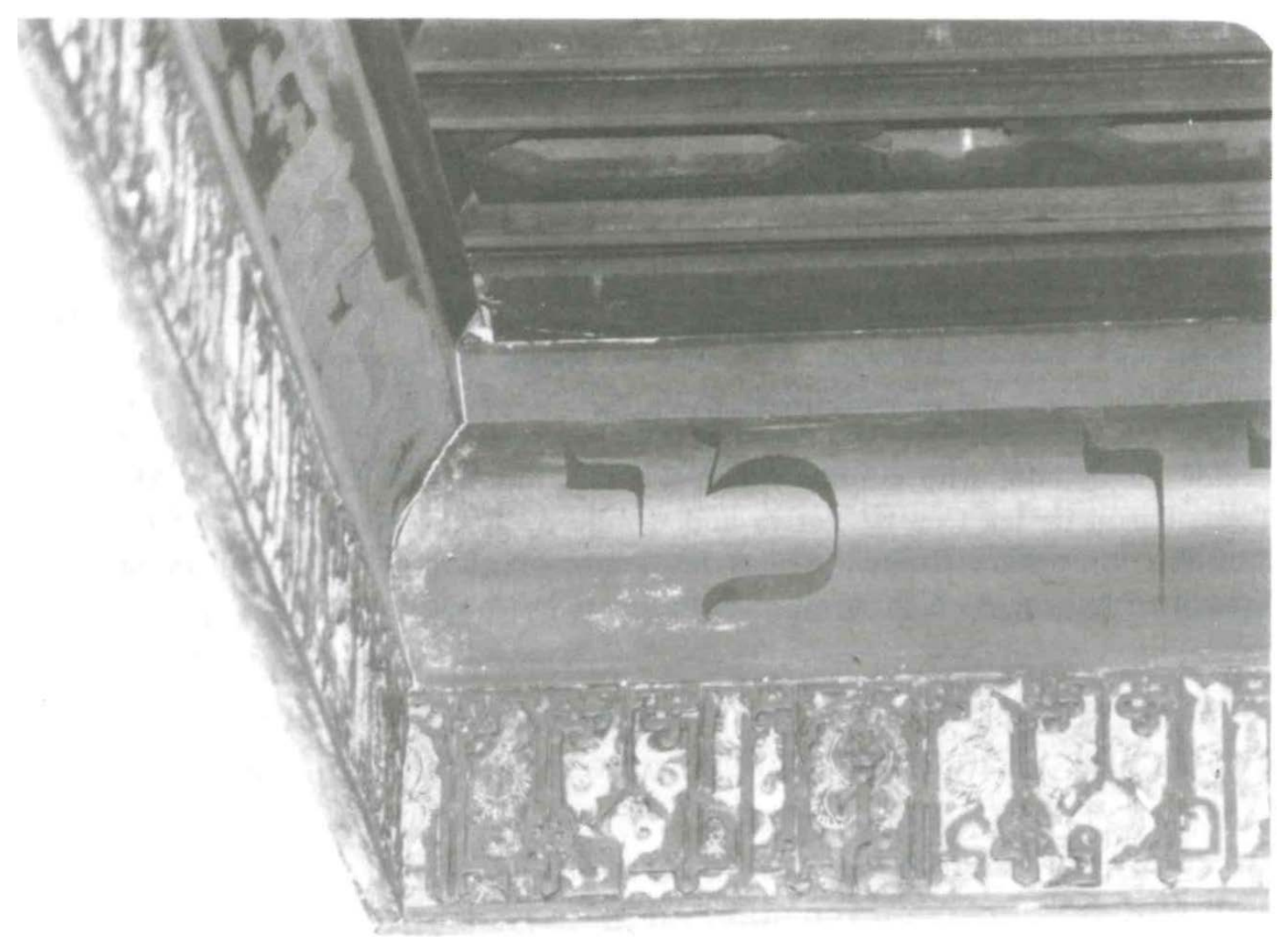

Detalle de la inscripción 


\section{RESUMEN}

En el castillo de Guadamur situado a $14 \mathrm{~km}$. de Toledo, construído en el reinado de Enrique IV de Castilla por don Pedro López de Ayala "el mozo", existe una inscripción hebrea bajo el artesonado de la habitación conocida como "drabe", con los versículos 2-4 y la primera palabra del 5 del Salmo 30, realizada durante la restauración del citado castillo en el siglo XIX. Posiblemente el conde de Cedillo que colaboró en la restauración con el dueño del castillo en esa época, don Carlos Morenes y Tord, Barón de las Cuatro Torres y Conde del Asalto, se inspiró en una inscripción similar existente en la galería de mujeres de la Sinagoga del Tránsito y hoy perdida en gran parte.

\section{SUMMARY}

Fourteen kilometres away from Toledo, in the Castle of Guadamur, built by Don Pedro López de Ayala "The Younger" during the reign of Henry IV of Castille, there is a Hebrew inscription under the coffered ceiling of the so-called "Arabic Hall", containing verses $2-4$ and the first word of verse 5 of Psalm 30, that was carved during the restoration of the castle in the 19th centrury. It is very likely that the Conde de Cedillo, who cooperated in the restoration with Don Carlos Morenes y Tord, Barón de las Cuatro Torres and Conde de Asalto, then owner of the castle, drew his inspiration from a similar inscription of the Women's Gallery in the El Tránsito Synagogue which, most of it, has gone last nowadays. 